\title{
Avaliação nutricional da silagem de raiz de mandioca contendo soja integral para leitões na fase inicial ${ }^{1}$
}

\section{Marcos Augusto Alves da Silva ${ }^{2}$, Antonio Claudio Furlan ${ }^{3}$, Ivan Moreira ${ }^{3}$, Diovani Paiano ${ }^{4}$, Carina Scherer ${ }^{4}$, Elias Nunes Martins ${ }^{3}$}

\author{
${ }_{1}^{1}$ Pesquisa parcialmente financiada pelo CNPq. \\ 2 Fundação Faculdades Luiz Meneguel - FFALM-UENP - Bandeirantes-PR. \\ ${ }^{3}$ Departamento de Zootecnia da UEM - Maringá-PR. \\ 4 Programa de Pós-Graduação em Zootecnia - PPZ - UEM - Maringá-PR.
}

RESUMO - Dois experimentos foram conduzidos para determinar o valor nutritivo e verificar o desempenho de leitões alimentados com rações formuladas com silagem de raiz de mandioca contendo ou não soja integral. No primeiro experimento, foram utilizados 15 machos castrados, mestiços, com peso corporal de 21,90 $\pm 2,54 \mathrm{~kg}$, distribuídos em delineamento inteiramente casualizado em parcelas (animais) subdivididas no tempo (subparcelas), totalizando cinco tratamentos e seis repetições. Foram avaliadas quatro silagens de raiz de mandioca: sem aditivos (MA); com inoculante (MI); com soja integral (MS); e com soja integral + inoculante (MSI). Os teores digestíveis de matéria seca, proteína e extrato etéreo das silagens MS e MSI, e os de amido, matéria orgânica e energia e a energia metabolizável, em 87,45\% de matéria seca, da silagem sem aditivos foram, respectivamente, de 80,$95 ; 1,82 ; 75,01 ; 77,31 \% ; 3.249$ e $3.184 \mathrm{kcal} / \mathrm{kg}$; os da silagem com inoculante foram 82,30 ; 1,$95 ; 74,65 ; 81,81 \% ; 3.292$ e $3.271 \mathrm{kcal} / \mathrm{kg}$; da silagem com soja integral 80,08; 6,69; 2,35; 64,18; 79,25\%; 3.452 e $3.370 \mathrm{kcal} / \mathrm{kg}$; e da silagem com soja integral + inoculante foram 79,22;6,73;2,20;66,79; 78,46\%; 3.342 e $3.303 \mathrm{kcal} / \mathrm{kg}$. $\mathrm{O}$ uso de inoculante não melhorou a digestibilidade dos nutrientes. No segundo experimento, foram utilizados 36 leitões com peso inicial de $14,67 \pm 1,07 \mathrm{~kg}$, distribuídos em delineamento inteiramente casualizado em esquema fatorial $3 \times 2$ (três alimentos e duas classes de peso), com seis repetições e dois animais por unidade experimental. Os tratamentos consistiram de uma ração-referência, à base de milho e farelo de soja, e de outras duas com substituição total do milho por silagem de raiz de mandioca contendo ou não soja integral. O fornecimento de silagem de mandioca + soja prejudicou o ganho de peso diário, enquanto a silagem de mandioca + soja e a ração à base de milho e farelo de soja pioraram a conversão alimentar dos animais. Silagens de raiz de mandioca, contendo ou não soja integral, apresentam bom valor nutritivo e podem ser utilizadas sem restrições na alimentação de leitões na fase inicial.

Palavras-chave: alimentos alternativos, desempenho, digestibilidade, suíno, valores energéticos

\section{Nutritional evaluation of cassava root silage with or without whole soybean for nursery piglets}

\begin{abstract}
Two experiments were carried out to determine nutritive value and verify performance of piglets fed diets with by cassava root silage with or without whole soybean. In the first experiment, 15 crossbred barrows with initial $\mathrm{BW}$ of $21.90 \pm 2.54 \mathrm{~kg}$ were allotted to a split plot design, whole plot (animals) and plot (time) with five diets and six repetitions. Four cassava root silages were evaluated: without inoculant (CA), with inoculant (CI), with integral soy (CS), and with integral soy and inoculant (CSI). The digestible values of dry matter, protein and ether extract of CS and CSI silages and of starch, organic matter and energy andthe metabolizable energy were 80.95, 1.82, 75.01, 77.31\%, 3,249 and $3,184 \mathrm{kcal} / \mathrm{kg}$ for CA; $82.30,1.95,74.65,81.81 \%, 3,292$ and $3,271 \mathrm{kcal} / \mathrm{kg}$ for CI; 80.08, 6.69, 2.35, 64.18, 79.25\%, 3,452 and $3,370 \mathrm{kcal} / \mathrm{kg}$ for CS and $79.22,6.73,2.20,66.79,78.46 \%, 3,342$ and $3,303 \mathrm{kcal} / \mathrm{kg}$ for CSI, respectively, based on $85.45 \%$ dry matter. The use of inoculant bacterial enzyme was not effective to improve nutrients digestibility. In the second experiment, 36 crossbred piglets with initial $14.67 \pm 1.07 \mathrm{~kg} \mathrm{BW}$ were assigned to a completely randomized design in a $3 \times 2$ factorial arrangement (feed and weight classes), with six replications and two piglets per experimental unit. The treatments consisted of a corn-soy meal based diet and other two diets with total cornreplacement by cassava root silage with or without whole soybean. The offer of cassava silage + soybean decreased average daily gain, while the cassava silage + soybean and corn-soy meal based diet worst feed:gain of the piglets. Cassava root silage, with or without whole soybean, showed higher nutritive value and could be used without restriction in piglet feeding in the initial phase.
\end{abstract}

Key Words: alternative foods, digestibility, energy values, performance, swine 


\section{Introdução}

A alimentação de suínos representa 70 a $80 \%$ do custo da produção e tem como principal fonte energética o milho seco moído, responsável pela maior parte dos custos da produção de rações. Assim, a busca por alimentos que possam otimizar os índices produtivos e econômicos nos sistemas de exploração pecuários sem comprometer o desempenho animal tem sido uma preocupação constante entre pesquisadores.

A mandioca (Manihot esculenta, Crantz) também conhecida como macaxeira ou aipim, é cultivada praticamente em todo território brasileiro e possui excelente qualidade nutritiva para a alimentação animal. Segundo Bezerra et al. (1996), a produção de mandioca exige menos insumos em comparação à maioria das culturas, o que a torna menos dispendiosa. Além disso, é uma atividade de grande expressão socioeconômica, tanto em nível nacional como mundial, e a mandioca constitui-se importante fonte de energia para a alimentação humana e animal.

O Brasil produz 23,8 milhões de toneladas. O estado do Paraná é o terceiro maior produtor nacional de raiz, 4,0 milhões de toneladas, e se destaca pelo maior e mais moderno parque industrial, especialmente o feculeiro (SEAB, 2005).

A raiz de mandioca é rica em amido e apresenta a seguinte composição química média: 60 a $65 \%$ de umidade; 21 a $33 \%$ de amido; 1,0 a 1,5\% de proteínas; 0,7 a 1,06\% de fibras; e 0,6 a 0,9\% de cinzas. Essa composição pode variar conforme as condições ambientais, o cultivar utilizado e a idade da planta (Butolo, 2002).

Estudos indicam que a raiz de mandioca pode ser incluída na formulação de rações para todos os animais domésticos, graças ao seu valor energético e à sua palatabilidade, no entanto, é necessário que a formulação contenha uma fonte protéica. Segundo Carvalho (1986), a mandioca pode ser classificada em dois tipos: a mansa, doce ou de mesa, que possui baixo teor de glicosídeo cianogênico (que resulta no ácido cianídrico), cuja concentração é inferior a $50 \mathrm{mg} / \mathrm{kg}$ na polpa fresca; e a brava, amarga ou venenosa, que possui teores elevados deste composto, superiores a $100 \mathrm{mg} / \mathrm{kg}$ na polpa fresca.

Os glicosídeos cianogênicos, sob hidrólise ácida no trato digestório ou sob ação de enzimas presentes na polpa (linamarase), produzem o ácido cianídrico (HCN), um produto tóxico que pode levar os animais à morte (Mazzuco \& Bertol, 2000). Contudo, a armazenagem em anaerobiose da raiz de mandioca reduz o teor de $\mathrm{HCN}$ em mais de $65 \%$ após 29 dias de ensilagem (Soares, 2003).
Para suínos, a raiz de mandioca e seus subprodutos podem ser utilizados com poucas restrições e constitui excelente substituto aos grãos de cereais. Buitrago (1990) afirma que dietas para suínos podem conter até $40 \%$ de raspa de mandioca e esse percentual pode ser aumentado quando os animais atingem as fases de crescimento e terminação.

Considerando que a produção de mandioca tem aumentado significativamente nas propriedades agrícolas brasileiras e paranaenses e que a literatura nacional é escassa quanto à utilização da silagem de raiz de mandioca na alimentação animal, justifica-se a realização de mais pesquisas para avaliação do desempenho de suínos alimentados com esse produto.

Neste trabalho, avaliou-se, por meio de ensaio de digestibilidade e desempenho, o uso de silagem de raiz de mandioca contendo ou não soja integral para leitões na fase de creche.

\section{Material e Métodos}

Foram conduzidos dois experimentos no Setor de Suinocultura da Fazenda Experimental de Iguatemi (FEI), pertencente ao Centro de Ciências Agrárias da Universidade Estadual de Maringá (CCA/UEM). No ensaio de digestibilidade, realizado no período de 7 a 21 de janeiro de 2005, foram utilizados 15 suínos (Landrace $\times$ Large White $\times$ Duroc), machos castrados, com 21,90 $\pm 2,54 \mathrm{~kg}$ de peso corporal inicial.

Os animais foram alojados individualmente em gaiolas semelhantes às descritas por Pekas (1968). O período experimental teve duração de cinco dias de adaptação às rações experimentais e às gaiolas, seguidos de dois períodos de cinco dias para coleta de fezes e urina. O delineamento experimental utilizado foi o inteiramente casualizado em parcelas (animais) subdivididas no tempo (subparcelas), totalizando cinco tratamentos com seis repetições, no qual a unidade experimental foi constituída por um suíno.

A variedade de mandioca (Manihot esculenta, Crantz) utilizada na produção das silagens foi a da Fécula Branca. Foram avaliadas quatro silagens de raiz de mandioca: sem aditivos (MA); com inoculante enzimobacteriano Bacto Silo, produzido pela Katec Agrotécnica (MI); com soja integral (MS); e com soja integral + inoculante (MSI). As silagens foram utilizadas em substituição, com base na matéria seca (MS), a 30\% da ração-referência (RR) e resultou em quatro rações-teste (RT). As rações que continham as silagens foram misturadas diariamente.

As raízes de mandioca utilizadas na confecção da silagem de mandioca sem aditivos ou contendo inoculante 
foram trituradas em moinho do tipo martelo e, em seguida, foram ensiladas em tambores de polietileno com capacidade para 200 litros. Nas silagens com soja integral, foram misturados $93 \%$ de raiz de mandioca triturada e $7 \%$ de soja integral para que a mistura apresentasse aproximadamente o nível de proteína bruta do milho em grão: 8,68\% em $87,45 \%$ MS, segundo Tabelas da EMBRAPA (1991). Posteriormente, foram também ensiladas em tambores de polietileno com capacidade para 200 litros.

A ração-referência (Tabela 1) foi formulada de acordo com a composição química e os valores energéticos dos ingredientes, por Rostagno et al. (2000).

As rações foram fornecidas duas vezes ao dia: $50 \%$ às $8 \mathrm{~h}$ e $50 \%$ às $16 \mathrm{~h}$. A quantidade total diária foi estabelecida de acordo com o consumo observado na fase de adaptação, baseado no peso metabólico $\left(\mathrm{kg}^{0,75}\right)$ de cada unidade experimental. No segundo período de coletas, o fornecimento de ração foi aumentado em $8 \%$ para todos os animais.

Depois de cada refeição, foi fornecida água no comedouro, na proporção de $3,0 \mathrm{~mL} / \mathrm{g}$ de ração, calculada para cada unidade experimental, para evitar o consumo excessivo de água. Utilizou-se o método de coleta total de fezes, com adição de $2 \%$ de óxido férrico $\left(\mathrm{Fe}_{2} \mathrm{O}_{3}\right)$ às rações como marcador do início e do fim da coleta de fezes.

As fezes totais produzidas foram coletadas uma vez ao dia em sacos plásticos e armazenadas em congelador a $-18^{\circ} \mathrm{C}$. Posteriormente, as fezes foram homogeneizadas e

Tabela 1 - Composição da ração-referência

\begin{tabular}{lc}
\hline Ingrediente & $\%$ \\
\hline Milho comum & 60,03 \\
Farelo de soja & 32,73 \\
Calcário & 0,73 \\
Fosfato bicálcico & 1,73 \\
Sal & 0,40 \\
Açúcar & 3,00 \\
Óleo vegetal & 0,88 \\
Suplemente vitamínico + mineral $^{1}$ & 0,50 \\
Total & 100,00
\end{tabular}

\section{Nutriente}

\section{Proteína bruta, \%}

Energia digestível, $\mathrm{kcal} / \mathrm{kg}$

Lisina total, \%

Metionina + cistina total, \%

Cálcio, \%

Fósforo disponível, \%

${ }_{1}$ Roche inicial - contendo por quilo do produto: vit. A - 2.000.000 UI vit. D3 - $400.000 \mathrm{UI}$; vit. E - $5.000 \mathrm{UI}$; vit. K3 - $400 \mathrm{mg}$; vit. B1 - $400 \mathrm{mg}$; vit. B2 - $1.200 \mathrm{mg}$; vit. B6 - $600 \mathrm{mg}$; vit. B12 - $6.000 \mathrm{mcg}$; ácido nicotínico - $6.000 \mathrm{mg}$; ácido pantotênico - $2.400 \mathrm{mg}$; biotina - $20 \mathrm{mg}$; ácido fólico 200 mg; Se - 60 mg; colina - $30.000 \mathrm{mg}$; lisina - $234.000 \mathrm{mg}$; promotor do crescimento - $10.000 \mathrm{mg}$; antioxidante $-20.000 \mathrm{mg}$; - $300 \mathrm{mg}$; Co - $200 \mathrm{mg}$; $\mathrm{Cu}-35.000 \mathrm{mg} ; \mathrm{Zn}-20.000 \mathrm{mg}$; Fe $-20.000 \mathrm{mg}$; Mn - $8.000 \mathrm{mg}$. uma amostra de $20 \%$ foi retirada, seca em estufa de ventilação forçada $\left(55^{\circ} \mathrm{C}\right)$ e moída para análise e determinação dos teores de MS, proteína bruta, extrato etéreo, amido, matéria orgânica (MO) e energia bruta. Os teores de energia bruta das rações, das silagens, das fezes e da urina foram determinados utilizando-se calorímetro adiabático (Parr Instrument Co.).

A urina foi coletada diariamente em baldes plásticos contendo $20 \mathrm{~mL}$ de $\mathrm{HCl}$ 1:1. Uma alíquota de $20 \%$ foi acumulada diariamente e congelada a $-18^{\circ} \mathrm{C}$. Posteriormente, todas as alíquotas foram homogeneizadas e amostradas para determinação do nível de energia.

As análises dos alimentos, das fezes e da urina foram realizadas no Laboratório de Nutrição Animal do Departamento de Zootecnia da Universidade Estadual de Maringá (LANA-DZO/UEM), segundo procedimentos descritos por Silva \& Queiroz (2002). As determinações de amido dos alimentos e das fezes foram obtidas de acordo com o método enzimático proposto por Poore et al. (1989), adaptado por Pereira \& Rossi (1995). Os valores de $\mathrm{pH}$ dos alimentos e das rações foram determinados pelo método utilizado por Phillip \& Fellner (1992).

Os coeficientes de digestibilidade de MS, proteína bruta (PB), extrato etéreo (EE), MS indigestível e amido digestível, amido, MO e energia bruta (EB) e do coeficiente de metabolização da energia bruta (EB) dos alimentos avaliados foram calculados considerando o método de coleta total de fezes e urina usado por Moreira et al. (1994).

Os teores de MS digestível (MSD), proteína digestível (PD), extrato etéreo digestível (EED) para soja integral (MS) e soja integral e inoculante (MSI), amido digestível (AMD), MO digestível (MOD), energia digestível (ED) e energia metabolizável (EM) dos alimentos foram calculados utilizando-se a fórmula de Matterson et al. (1965).

No experimento para análise do desempenho dos leitões na fase pré-inicial, realizado no período de 23 de maio a 16 de junho de 2005, foram utilizados 36 suínos mestiços machos castrados e fêmeas, com peso inicial de $14,67 \pm 1,07 \mathrm{~kg}$, mantidos no experimento durante 25 dias até atingirem $31,77 \pm 2,10 \mathrm{~kg}$ de peso corporal.

O delineamento experimental utilizado foi o inteiramente casualizado em esquema fatorial $3 \times 2$, composto de três tratamentos e duas classes de peso, com seis repetições, no qual a unidade experimental foi formada por um macho e uma fêmea. Os animais foram pesados no início e ao final do período experimental. Durante o experimento, foram alojados em galpão de alvenaria coberto com telhas de fibrocimento, composto de duas salas, cada uma com dez baias, divididas por um corredor central. As baias eram do tipo suspensas, com piso de plástico, equipadas com 
comedouro de cinco bocas localizado na parte frontal e um bebedouro tipo chupeta na parte posterior.

Os tratamentos consistiram de uma ração-referência (RR), à base de milho seco, e outras duas rações experimentais - todas isoenergéticas, isocálcicas, isofosfóricas e isoprotéicas - em que o milho seco foi totalmente substituído (100\%) por silagem de raiz de mandioca com ou sem soja integral e os valores energéticos foram convertidos para $87,45 \%$ MS. As rações foram formuladas de acordo com as tabelas de exigências nutricionais propostas por Rostagno et al. (2000) para leitões em fase de creche (Tabela 2).

As raízes de mandioca utilizadas na confecção da silagem de raiz de mandoca foram trituradas em ensiladeira e ensiladas em trincheira com capacidade para 6 toneladas. $\mathrm{Na}$ confecção das silagens de raiz de mandioca com soja integral, utilizaram-se as mesmas raízes de mandioca trituradas, que foram misturadas (93\%) com $7 \%$ de soja integral - quantidade suficiente para que a mistura atingisse aproximadamente o nível de proteína bruta do milho grão de 8,68\% em 87,45\% MS, segundo Tabelas da EMBRAPA (1991) - e também ensiladas em silo trincheira com mesma capacidade.

As rações formuladas com silagem de mandioca e com silagem de mandioca contendo soja integral foram misturadas diariamente a um concentrado previamente preparado. As rações foram pesadas diariamente e fornecidas na forma farelada. A água e as rações foram fornecidas à vontade.

Os valores de $\mathrm{pH}$ das silagens foram obtidos segundo procedimentos utilizados por Phillip \& Fellner (1992). Os valores de ácido cianídrico e inibidores de tripsina das silagens antes e depois da ensilagem foram obtidos utilizando-se metodologia de Horwitz (1975) e Rackis et al. (1974), respectivamente. O consumo diário de ração (CDR), o ganho de peso diário (GPD) e a conversão alimentar (CA) foram calculados utilizando-se os dados de consumo de ração e ganho de peso obtidos durante o período experimental.

Os preços dos ingredientes utilizados na elaboração das dietas experimentais foram: milho grão, $\mathrm{R} \$ 0,21 / \mathrm{kg}$; farelo de soja, $\mathrm{R} \$ 0,52 / \mathrm{kg}$; óleo de soja, $\mathrm{R} \$ 1,44 / \mathrm{kg}$; fosfato bicálcico, $\mathrm{R} \$ 1,32 / \mathrm{kg}$; calcário, $\mathrm{R} \$ 0,15 / \mathrm{kg}$; sal comum, $\mathrm{R} \$ 0,34 / \mathrm{kg}$; suplemento mineral e vitamínico inicial $\mathrm{R} \$ 3,47 / \mathrm{kg}$; L-lisina, R \$ 6,93/kg; e DL-metionina, R \$ 9,15/kg. Os preços da silagem de mandioca e da silagem de mandioca contendo soja integral foram de $\mathrm{R} \$ 0,18 / \mathrm{kg}$ e $\mathrm{R} \$ 0,20 / \mathrm{kg}$, respectivamente, quando ajustados para a mesma base de MS do milho seco $(87,45 \%)$ - estimativa feita de acordo com o custo da tonelada de raiz de mandioca $(\mathrm{R} \$ 90,00)$.
Tabela 2 - Composição das rações experimentais

\begin{tabular}{|c|c|c|c|}
\hline \multirow[b]{2}{*}{ Ingrediente } & \multicolumn{3}{|c|}{ ão-referência } \\
\hline & & $\begin{array}{l}\text { Com silagem } \\
\text { de raiz de } \\
\text { mandioca }\end{array}$ & $\begin{array}{l}\text { Com silagem } \\
\text { de raiz de } \\
\text { mandioca } \\
+ \text { soja integral }\end{array}$ \\
\hline${ }^{1}$ Milho moído & 65,05 & - & - \\
\hline $\begin{array}{l}\text { Silagem de raiz de } \\
\text { mandioca (MA) }\end{array}$ & - & $54,15(108,91)^{2}$ & - \\
\hline MA com soja integral & - & - & $65,38(127,85)^{2}$ \\
\hline Farelo de soja & 30,10 & 38,72 & 29,65 \\
\hline Óleo soja & 1,45 & 3,92 & 1,75 \\
\hline Fosfato bicálcico & 1,75 & 1,86 & 1,85 \\
\hline Calcário & 0,70 & 0,40 & 0,42 \\
\hline Sal comum & 0,40 & 0,40 & 0,40 \\
\hline $\begin{array}{l}\text { Suplemento vitamínico } \\
\text { e mineral }{ }^{3}\end{array}$ & 0,50 & 0,50 & 0,50 \\
\hline L-lisina $\mathrm{HCl}$ & 0,05 & - & - \\
\hline DL-metionina & - & 0,06 & 0,06 \\
\hline $\begin{array}{l}\text { Total } \\
\text { Nutriente }\end{array}$ & 100 & 100 & 100 \\
\hline $\begin{array}{l}\text { Energia digestível } \\
(\mathrm{kcal} / \mathrm{kg})\end{array}$ & 3.400 & 3.400 & 3.400 \\
\hline Proteína bruta, \% & 19,00 & 19,00 & 19,00 \\
\hline Lisina total, \% & 1,06 & 1,17 & 1,15 \\
\hline $\begin{array}{l}\text { Metionina + cistina } \\
\text { total, } \%\end{array}$ & 0,64 & 0,63 & 0,63 \\
\hline $\mathrm{Ca}, \%$ & 0,83 & 0,83 & 0,83 \\
\hline $\mathrm{P}$ disponível, \% & 0,43 & 0,43 & 0,43 \\
\hline
\end{tabular}

1 Valores em $87,45 \%$ de matéria seca

2 Valores na matéria natural.

3 Suplemento vitamínico-mineral. Conteúdo por $\mathrm{kg}$ de ração: vit. A 2.000.000 UI; vit. $D_{3}-400.000$ UI; vit. E - $5.000 \mathrm{UI}$; vit. $\mathrm{K}_{3}-400,0 \mathrm{mg}$; vit. $B_{1}-400,0 \mathrm{mg}$; vit. $B_{2}-1200,0 \mathrm{mg}$; vit. $B_{6}-600,0 \mathrm{mg}$; vit. $B_{12}-$ $6.000,0 \mathrm{mcg}$; ácido nicotínico - 6.000,0 mg;ácido pantotênico - $2.400,0 \mathrm{mg}$; biotina - 20,0 mg; ácido fólico - 200,0 mg; Se - 60,0 mg; colina - $30,0 \mathrm{~g}$; lisina - $234,0 \mathrm{~g}$; salinomicina - $10.000,0 \mathrm{mg}$; antioxidante - $20,0 \mathrm{~g} ; \mathrm{I}-300,0 \mathrm{mg}$ Co - 200,0 mg; Cu - 35.000,0 mg; Zn - 20.000,0 mg; Fe - 20.000,0 mg; $\mathrm{Mn}-8.000,0 \mathrm{mg}$; veículo q.s.p. - $1.000,0 \mathrm{~g}$

A viabilidade econômica da substituição do milho por silagem de raiz de mandioca contendo ou não soja integral nas rações foi determinada utilizando-se inicialmente o custo de ração por quilograma de peso corporal ganho (Yi), conforme descrito por Bellaver et al. (1985).

Em seguida, foram calculados o índice de eficiência econômica (IEE) e o índice de custo (IC), proposto por Gomes et al. (1991). Os dados obtidos para o consumo diário de ração, o ganho diário de peso, a conversão alimentar e as variáveis econômicas foram submetidos à análise de variância pelo programa Sistema de Análises Estatísticas e Genéticas - SAEG(UFV, 1997).

Na comparação dos resultados obtidos com as rações experimentais, aplicou-se o teste Tukey a 5\%.

\section{Resultados e Discussão}

Quando convertidos para mesma base de MS (87,45\% MS), os teores de proteína bruta, cinzas, extrato etéreo, 
fibra bruta e energia bruta da silagem de raiz de mandioca sem aditivos e da silagem contendo inoculante foram menores que os encontrados para a silagem com soja integral e para aquela com soja integral + inoculante (Tabela 3). Este resultado está relacionado à inclusão de soja integral nessas duas últimas silagens, o que aumentou seus teores de energia, fibra, extrato etéreo e proteína bruta, como resultado dos maiores teores de óleo, fibra e proteína bruta do grão de soja.

Os teores de energia bruta e proteína bruta das silagens contendo soja foram 8,3 e $249,6 \%$ superiores aos das silagens de mandioca sem soja.

Os valores de $\mathrm{pH}$ das silagens estudadas podem ser considerados satisfatórios, pois foram inferiores a 4, valor adequado para a maioria das silagens. Esses valores foram próximos aos citados por Jobim et al. (1997) e Lima et al. (1998), de 3,6 e 4,0, respectivamente, para silagens de grãos úmidos de milho.

Em valores convertidos para $87,45 \%$ de MS, as silagens de raiz de mandioca e de raiz de mandioca com inoculante apresentaram teores de energia bruta inferiores e proteína bruta superiores aos descritos por Rostagno et al. (2005), EMBRAPA (1991) e Butolo (2002) para a raspa de mandioca integral (3.632 kcal/kg e 1,7\%; $3.595 \mathrm{kcal} / \mathrm{kg}$ e 1,98\%; 3.692 $\mathrm{kcal} / \mathrm{kg}$ e $1,94 \%$ respectivamente). Em comparação à silagem de raiz de mandioca obtida pela EMBRAPA (1991), os teores de energia e proteína bruta da silagem de raiz de mandioca contendo ou não inoculante foram superiores $(3.386 \mathrm{kcal} / \mathrm{kg}$ e $2,60 \%$ ).

Os teores ácidos cianídricos e inibidores de tripsina (Tabela 4) da silagem de raiz de mandioca contendo ou não soja integral diminuíram após a ensilagem, o que confirma o efeito positivo da fermentação anaeróbia durante o pro- cesso de ensilagem. Resultado similar foi encontrado em silagem de folhas e ramos de mandioca por Soares (2003), que observou redução de $78 \%$ no teor de ácido cianídrico. Entretanto, os teores de ácido cianídrico da raiz de mandioca antes da ensilagem foram baixos, o que caracterizam a mandioca utilizada no experimento como variedade mansa, segundo critério descrito por Carvalho (1986) de que mandioca mansa, doce ou de mesa possui teor de ácido cianídrico inferior a $50 \mathrm{mg} / \mathrm{kg}$ de polpa fresca.

Os coeficientes de digestibilidade da proteína bruta obtidos para as silagens de raiz de mandioca com e sem inoculante (55,77 e 57,54\%, respectivamente) foram menores $(\mathrm{P}<0,05)$ que os encontrados para as silagens som soja integral e com soja integral + inoculante $(80,92$ e 80,50\%, respectivamente). Esse aumento no coeficiente pode ser atribuído à mais alta qualidade e ao maior teor de proteína bruta dessas silagens, ocasionados pela inclusão de soja integral (Tabela 5).

Os coeficientes de metabolização da energia bruta e da energia metabolizável das silagens de raiz de mandioca com soja integral e com soja integral + inoculante foram inferiores $(\mathrm{P}<0,05)$ aos obtidos para a silagem contendo ou não inoculante. Essa redução nos coeficientes podem ter sido causadas pelo aumento no teor de fibra bruta daquelas silagens com soja integral.

O coeficiente de metabolização da energia bruta, o de digestibilidade de proteína bruta e o de metabolização da energia metabolizável obtidos para os alimentos avaliados neste experimento foram inferiores aos descritos pela EMBRAPA (1991) para silagem de raiz de mandioca (95,97; 76,67 e 91,49\%, respectivamente), com exceção do coeficiente de digestibilidade da proteína bruta da silagem com soja integral e da silagem com soja integral + inoculante e do

Tabela 3 - Composição química das silagens avaliadas

\begin{tabular}{|c|c|c|c|c|c|c|c|c|}
\hline \multirow[b]{3}{*}{ Nutriente } & \multicolumn{8}{|c|}{ Silagem de raiz de mandioca } \\
\hline & \multicolumn{4}{|c|}{$\%$ matéria natural } & \multicolumn{4}{|c|}{ Em $87,45 \%$ de matéria seca ${ }^{1}$} \\
\hline & $\begin{array}{l}\text { S/ aditivos } \\
\text { (MA) }\end{array}$ & $\mathrm{C} /$ inoculante & $\begin{array}{l}\mathrm{C} / \text { soja } \\
\text { integral }\end{array}$ & $\begin{array}{l}\text { C/ soja integral } \\
\text { e inoculante }\end{array}$ & $\begin{array}{l}\text { S/ aditivos } \\
\text { (MA) }\end{array}$ & $\mathrm{C} /$ inoculante & $\begin{array}{c}\mathrm{C} / \text { soja integral } \\
\text { integral }\end{array}$ & $\begin{array}{l}\text { C/ soja integral } \\
\text { e inoculante }\end{array}$ \\
\hline Matéria seca, \% & 46,15 & 45,75 & 45,37 & 44,15 & 87,45 & 87,45 & 87,45 & 87,45 \\
\hline Proteína bruta, \% & 1,72 & 1,77 & 4,29 & 4,23 & 3,27 & 3,39 & 8,27 & 8,36 \\
\hline Amido, \% & 39,58 & 39,06 & 33,30 & 33,72 & 75,01 & 74,65 & 64,18 & 66,79 \\
\hline Matéria orgânica, \% & 45,29 & 44,89 & 44,25 & 43,10 & 85,86 & 85,80 & 85,31 & 85,38 \\
\hline Cinzas, \% & 0,83 & 0,86 & 1,12 & 1,05 & 1,58 & 1,65 & 2,15 & 2,08 \\
\hline Extrato etéreo, \% & 0,13 & 0,12 & 1,61 & 1,49 & 0,24 & 0,22 & 3,12 & 3,11 \\
\hline Fibra bruta, \% & 1,26 & 1,36 & 1,87 & 2,06 & 2,39 & 2,60 & 3,61 & 4,08 \\
\hline Cálcio, \% & 0,08 & 0,08 & 0,08 & 0,08 & 0,15 & 0,15 & 0,16 & 0,16 \\
\hline Fósforo total, \% & 0,04 & 0,04 & 0,05 & 0,05 & 0,07 & 0,07 & 0,10 & 0,10 \\
\hline Energia bruta, $\mathrm{kcal} / \mathrm{kg}$ & 1.873 & 1.845 & 2.002 & 1.922 & 3.550 & 3.527 & 3.858 & 3.806 \\
\hline $\mathrm{pH}$ & 3,90 & 3,84 & 3,98 & 3,97 & - & - & - & - \\
\hline
\end{tabular}

${ }^{1}$ Conforme os dados descritos na tabela da EMBRAPA (1991) para o milho (grão). 
Tabela 4 - Teores de ácido cianídrico e inibidores de tripsina de silagens de raiz de mandioca

\begin{tabular}{lccccc}
\hline \multirow{2}{*}{ Parâmetro } & \multicolumn{3}{c}{ Silagem de raiz de mandioca } \\
\cline { 2 - 3 } \cline { 5 - 6 } & \multicolumn{2}{c}{ Sem soja integral } & & \multicolumn{2}{c}{ Com soja integral } \\
\cline { 2 - 3 } \cline { 5 - 6 } & Antes & Depois & & Antes & Depois \\
\hline $\begin{array}{l}\text { Ácido cianídrico } \\
\text { (mg/kg) }\end{array}$ & 35,2 & 12,0 & & $\mathrm{Nd}^{1}$ & $\mathrm{Nd}^{1}$ \\
$\begin{array}{l}\text { Inibidores de tripsinas } \\
\text { (UIT/g) }\end{array}$ & $\mathrm{Nd}^{1}$ & $\mathrm{Nd}^{1}$ & & 841,5 & 591,5 \\
\hline
\end{tabular}

${ }^{1}$ Não-determinado.

coeficiente de metabolização da energia bruta da silagem com inoculante, que foram superiores.

Em comparação aos descritos por Rostagno et al. (2005) para a raspa de mandioca integral $(84,18 ; 35,0$ e $83,40 \%$, respectivamente), os coeficientes de digestibilidade da energia bruta e da proteína bruta e o coeficiente de metabolização da energia bruta das silagens avaliadas foram maiores, evidenciando que o processo de ensilagem melhorou o valor nutricional da mandioca, fato que pode ser atribuído à acidificação do material ensilado, pois o $\mathrm{pH}$ reduziu para valores menores que quatro.

De acordo com Jongbloed et al. (2000), a utilização de ácidos orgânicos na dieta de suínos diminui o pH do alimento no trato gastrintestinal, que resulta em maior dissociação dos compostos minerais da dieta, proporcionando a formação de complexos minerais quelatados, melhorando a sanidade do intestino dos animais e reduzindo a taxa de esvaziamento gástrico, o que melhora a digestibilidade de MS, MO, cinzas, cálcio e fósforo.

Com o atraso no esvaziamento estomacal, é possível que a ação das enzimas digestivas, pepsina e lipase gástrica (Solomon, 1994), ocorra por mais tempo. Além disso, provavelmente a ação das enzimas digestivas é mais eficiente nas partículas úmidas do alimento. Holmes et al. (1973) constataram maiores coeficientes de digestibilidade ileal e total da MS, energia e proteína de dietas contendo milho úmido tratado com ácidos orgânicos ou silagem de grãos úmidos de milho, cujo $\mathrm{pH}$ variou entre 4,77 e 5,16 em comparação à dieta com milho seco comum ( $\mathrm{pH}=5,35)$. Como conseqüência, esses autores observaram menor quantidade de nutrientes (amido e compostos nitrogenados) fermentada no intestino grosso.

A digestibilidade do amido dos alimentos avaliados foi considerada total, corroborando os resultados descritos por Holmes et al. (1973) de que a concentração de amido nas fezes de $10 \mathrm{~g} / \mathrm{kg}$ representa menos de $0,2 \%$ do amido ingerido, o que dificulta a mensuração ao assumir a digestão completa do amido. A maior digestibilidade do amido da mandioca ensilada pode ser atribuída, sobretudo, à ausência da matriz protéica no grão de amido deste ingrediente, pois, de acordo com Rooney \& Pflugfelder (1986), as matrizes de proteína e os corpos protéicos presentes no endosperma dos grãos afetam a utilização deste carboidrato pelos animais. Essa maior digestibilidade pode estar relacionada à ação dos ácidos orgânicos formados na silagem, pois, segundo esses autores, o amido pode ser gelatinizado pela ação de agentes químicos como os ácidos orgânicos.

Os coeficientes de digestibilidade das silagens testadas não sofreram efeito da inclusão de inoculante enzimobacteriano, pois a raiz de mandioca possui grande quantidade de amido de fácil fermentação pelas bactérias. Como não houve diferença nos coeficientes de digestibilidade, optou-se por não colocar o inoculante nas silagens utilizadas no experimento de desempenho.

Para comparação dos dados obtidos (Tabela 6) aos da literatura, os teores de nutrientes digestíveis deste trabalho e os de outros autores foram convertidos para $87,45 \%$ de MS, com base na MS do milho, de acordo com a tabela da EMBRAPA (1991).

As silagens contendo soja integral e contendo soja integral + inoculante apresentaram em média $127 \mathrm{kcal}$ de energia digestível $/ \mathrm{kg}, 4,83 \%$ de proteína digestível e $109 \mathrm{kcal}$ de energia metabolizável $/ \mathrm{kg}$, valores superiores aos obtidos com as silagens de mandioca com e sem inoculante. Este resultado era esperado, pois, com a inclusão de soja integral na silagem de raiz de mandioca, aumentaram-se os teores de energia e proteína bruta dessas silagens, o que aumentou seus teores nutricionais.

Os valores de proteína e energia digestíveis e energia metabolizável das silagens de mandioca com e sem inoculante foram bem semelhantes e os das silagens com soja integral e com soja integral + inoculante foram superiores aos descritos pela EMBRAPA (1991), de 1,99\%, 3.250 e $3.098 \mathrm{kcal} / \mathrm{kg}$, respectivamente. Os valores de proteína digestível obtidos para as silagens de mandioca, com e sem inoculante, foram inferiores e os obtidos para as silagens com soja integral e com soja integral + incolante superiores aos descritos pela EMBRAPA (1991) para a raiz fresca, de $3,05 \%, 3.299$ e $2.788 \mathrm{kcal} / \mathrm{kg}$, respectivamente. No entanto, os valores de energia digestível das silagens de mandioca com e sem inoculante foram semelhantes; os das silagens com soja integral e com soja integral + inoculante superiores; e os de energia metabolizável de todas as silagens foram superiores aos reportados pela EMBRAPA (1991).

Os valores de proteína digestível, MO digestível, energia digestível e energia metabolizável das silagens testadas foram superiores aos reportados por Rostagno et al. (2005), de 0,$87 ; 72,79 \%, 3.040$ e $3.012 \mathrm{kcal} / \mathrm{kg}$, respectivamente, 
para raspa integral de mandioca, com exceção do valor de proteína digestível das silagens de raiz de mandioca com e sem incoluante, que foram bastante próximos. As silagens com soja integral e com soja integral + inoculante apresentaram teores de extrato etéreo superiores ao de $0,25 \%$ encontrado por esses autores para raspa integral de mandioca.

O consumo diário de ração não diferiu entre as dietas testadas $(P \geq 0,05)$, o que confirma a boa aceitação da silagem de raiz de mandioca com ou sem soja integral (Tabela 7). O ganho de peso foi maior $(\mathrm{P} \leq 0,05)$ nos leitões alimentados com dieta contendo silagem de raiz de man- dioca sem aditivos em comparação àqueles alimentados com a dieta contendo silagem com soja integral. A conversão alimentar foi melhor $(\mathrm{P} \leq 0,05)$ nos animais alimentados com a dieta contendo silagem de raiz de mandioca sem aditivos em comparação àqueles que receberam as dietas com silagem com soja integral ou a ração-referência.

A redução no ganho de peso e a pior conversão alimentar nos animais que receberam silagem de raiz de mandioca com soja integral pode ser atribuído aos fatores antinutricionais do grão de soja cru, pois provavelmente o processo de ensilagem não foi eficiente para inativar totalmente esses

Tabela 5 - Coeficientes de digestibilidade dos nutrientes e coeficiente de metabolização da energia bruta de silagens de raiz de mandioca

\begin{tabular}{|c|c|c|c|c|c|}
\hline \multirow[t]{2}{*}{ Item } & \multicolumn{4}{|c|}{ Silagem de raiz de mandioca } & \multirow[t]{2}{*}{$\mathrm{CV}(\%)^{1}$} \\
\hline & Sem aditivos (MA) & Com inoculante & Com soja integral & Com soja integral + inoculante & \\
\hline Matéria seca, \% & 92,57 & 94,11 & 91,57 & 90,59 & 1,29 \\
\hline Proteína bruta, \% & $55,77 b$ & $57,54 \mathrm{~b}$ & $80,92 \mathrm{a}$ & $80,50 a$ & 8,21 \\
\hline Extrato etéreo, \% & $\mathrm{Nd}^{2}$ & $\mathrm{Nd}^{2}$ & 75,48 & 70,89 & 9,46 \\
\hline Amido, \% & 100 & 100 & 100 & 100 & - \\
\hline Matéria orgânica, \% & $90,04 b$ & $95,35 \mathrm{a}$ & $92,90 \mathrm{ab}$ & $91,89 b$ & 1,01 \\
\hline $\mathrm{CMEB}^{3}, \%$ & $89,70 \mathrm{a}$ & $92,74 a$ & $87,34 b$ & $86,79 b$ & 1,81 \\
\hline
\end{tabular}

Médias na mesma linha seguidas por letras diferentes são diferentes $(P<0,05)$.

${ }^{1}$ Coeficiente de variação.

2 Não-determinado.

${ }^{3}$ Coeficiente de metabolização da energia bruta.

Tabela 6 - Composição nutricional de silagens de raiz de mandioca, na matéria natural e em $87,45 \%$ de matéria seca

\begin{tabular}{|c|c|c|c|c|c|c|c|c|}
\hline \multirow[b]{3}{*}{ Nutriente $(\%)$} & \multicolumn{8}{|c|}{ Silagem de raiz de mandioca } \\
\hline & \multicolumn{4}{|c|}{$\%$ matéria natural } & \multicolumn{4}{|c|}{ Em $87,45 \%$ de matéria seca } \\
\hline & $\begin{array}{l}\text { S/ aditivos } \\
\text { (MA) }\end{array}$ & $\mathrm{C} /$ inoculante & $\begin{array}{l}\text { C/ soja } \\
\text { integral }\end{array}$ & $\begin{array}{l}\text { C/ soja integral } \\
\text { e inoculante }\end{array}$ & $\begin{array}{l}\text { S/ aditivos } \\
\text { (MA) }\end{array}$ & $\mathrm{C} /$ inoculante & $\begin{array}{l}\mathrm{C} / \mathrm{soja} \text { integral } \\
\text { integral }\end{array}$ & $\begin{array}{l}\text { C/ soja integral } \\
\text { e inoculante }\end{array}$ \\
\hline MS digestível & 40,94 & 40,33 & 40,15 & 38,51 & 80,95 & 82,30 & 80,08 & 79,22 \\
\hline Proteína digestível & 0,92 & 0,96 & 3,36 & 3,28 & 1,82 & 1,95 & 6,69 & 6,73 \\
\hline Extrato etéreo digestíve & el $\mathrm{Nd}^{1}$ & $\mathrm{Nd}^{1}$ & 1,18 & 1,01 & $\mathrm{Nd}^{1}$ & $\mathrm{Nd}^{1}$ & 2,35 & 2,20 \\
\hline Amido digestível & 37,93 & 36,58 & 32,18 & 32,46 & 75,01 & 74,65 & 64,18 & 66,79 \\
\hline MO digestível, \% & 39,09 & 40,09 & 39,73 & 38,13 & 77,31 & 81,81 & 79,25 & 78,46 \\
\hline $\begin{array}{l}\text { Energia digestível, } \\
\mathrm{kcal} / \mathrm{kg}\end{array}$ & 1.643 & 1.613 & 1.731 & 1.624 & 3.249 & 3.292 & 3.452 & 3.342 \\
\hline $\begin{array}{l}\text { Energia metabolizável, } \\
\mathrm{kcal} / \mathrm{kg}\end{array}$ & 1.610 & 1.603 & 1.690 & 1.606 & 3.184 & 3.271 & 3.370 & 3.303 \\
\hline
\end{tabular}

${ }^{1}$ Não-determinado.

Tabela 7 - Desempenho dos animais e pH das rações experimentais

\begin{tabular}{lccc} 
& Ração-referência & \multicolumn{2}{c}{ Ração-teste $^{1}$} \\
\cline { 3 - 4 } Variável & & Com silagem de raiz de mandioca & $\begin{array}{c}\text { Com silagem de raiz de mandioca } \\
\text { com } \\
\text { soja integral }\end{array}$ \\
\hline Consumo diário de ração, kg/dia & 1,380 & 1,322 & 1,274 \\
Ganho de peso diário, kg/dia & $0,715 \mathrm{ab}$ & $0,774 \mathrm{a}$ & $0,677 \mathrm{~b}$ \\
Conversão alimentar & $1,930 \mathrm{a}$ & $1,702 \mathrm{~b}$ & $1,883 \mathrm{a}$ \\
pH da ração & 5,50 & 4,81 & 4,66
\end{tabular}

Médias na mesma linha seguidas por letras diferentes são diferentes $(P<0,05)$.

${ }^{1}$ Coeficiente de variação. 
fatores, apesar da redução na quantidade de unidades de inibidores de tripsina após a ensilagem.

A melhora na conversão alimentar dos leitões alimentados com silagem de raiz de mandioca pode ser resultado da ausência de inibidores de tripsina, associada à menor proporção de amilose nos grânulos de amido da mandioca em comparação aos do milho. Segundo Van Soest (1994), a digestibilidade do amido é inversamente proporcional à quantidade de amilose.

A redução do pH ocorreu nas duas silagens. De acordo com Holmes et al. (1974), o aumento da acidez total da dieta de suínos provocada pelo milho úmido preservado com ácidos orgânicos determinou maior tempo de retenção estomacal e fluxo mais homogêneo da digesta para o intestino delgado no intervalo das refeições, o que favorece o processo de digestão e explica a melhora em relação à ração-referência.

Os resultados obtidos com a análise econômica incluem o custo por tonelada da silagem de raiz de mandioca e da silagem de raiz de mandioca com soja integral ajustados para $87,45 \%$ de MS e do milho, de R \$180,00, R \$200,00 e $\mathrm{R} \$ 210,00$, respectivamente (Tabela 8). O custo de ração por quilograma de suíno produzido não diferiu $(\mathrm{P} \geq 0,05)$ entre as dietas testadas. Os valores de IEE e o IC foram bastante semelhantes e confirmam que a silagem de raiz de mandioca pode substituir totalmente o milho nas rações sem prejudicar o preço do quilo produzido.

Tabela 8 - Custo do quilograma de ração, custo de ração por quilograma de suíno produzido (CR), índice de eficiência econômica (IEE) e índice de custo (IC) das rações experimentais

\begin{tabular}{|c|c|c|c|c|c|}
\hline \multirow[t]{2}{*}{ Variável } & \multirow[b]{2}{*}{ Ração-referência } & \multicolumn{2}{|c|}{ Com silagem de raiz de mandioca } & \multirow[t]{2}{*}{$\mathrm{CV}^{1}, \%$} & \multirow[t]{2}{*}{ Efeito } \\
\hline & & Sem aditivo (MA) & Com soja integral & & \\
\hline Custo da ração, $\mathrm{R} \$ / \mathrm{kg}$ & 0,399 & 0,443 & 0,398 & - & \\
\hline Custo da ração ${ }^{2}$ & 0,769 & 0,755 & 0,749 & 5,07 & NS \\
\hline \multicolumn{6}{|l|}{ PV ganho } \\
\hline IEE & 97 & 99 & 100 & - & \\
\hline IC & 103 & 101 & 100 & - & \\
\hline
\end{tabular}

NS - não-significativo

1 Coeficiente de variação.

${ }^{2}$ Custo da ração por $\mathrm{kg}$ de PC ganho no período.

\section{Conclusões}

O uso de inoculante enzimobacteriano não melhorou a digestibilidade dos nutrientes de silagens de raiz de mandioca contendo ou não soja integral. Silagens de raiz de mandioca contendo ou não soja integral apresentam bom valor nutritivo e podem ser utilizadas na alimentação de leitões na fase de creche, pois não prejudicam o preço do quilo produzido.

\section{Literatura Citada}

BELLAVER, C.; FIALHO, E.T.; PROTAS, J.F.S. et al. Radícula de malte na alimentação de suínos em crescimento e terminação. Pesquisa Agropecuária Brasileira, v.20, n.8, p.969-974, 1985.

BEZERRA, I.L.; PEQUENO, P.L.L.; RIBEIRO, P.A. et al. Resposta da mandioca (macaxeira) a adubação com nitrogênio, fósforo e potássio em níveis crescentes. Sociedade Brasileira de Ciência do Solo. In: REUNIÃO BRASILEIRA DE FERTILIDADE DO SOLO E NUTRIÇÃO DE PLANTAS, 22., 1996, Manaus. Resumos... Manaus: [s.n.], 1996. p.26.

BUITRAGO, A. La yuca en la alimentacion animal. [S.1.]: Centro Internacional de Agricultura Tropical, 1990. 446p.

BUTOLO, J.E. Qualidade de ingredientes na alimentação animal. Campinas: Agros Comunicação, 2002. 420p.

CARVALHO, J.L.H. A mandioca: raiz, parte aérea e subprodutos da indústria na alimentação animal. In: CURSO INTENSIVO
NACIONAL DE MANDIOCA, 6., 1986, Cruz das Almas. Palestras... Cruz das Almas: CNPMF, EMBRAPA, 1986. p.92.

EMPRESA BRASILEIRA DE PESQUISA E AGROPECUÁRIA EMBRAPA. Tabela de composição química e valores energéticos de alimentos para suínos e aves. 3.ed. Concórdia: Embrapa - Centro Nacional de Pesquisa de Suínos e Aves, 1991. $97 \mathrm{p}$.

GOMES, M.F.M.; BARBOSA, H.P.; FIALHO, E.T. et al. Análise econômica da utilização do triguilho para suínos. (S.I): Embrapa - Centro Nacional de Pesquisa de Suínos e Aves, 1991. p.1-2. (Comunicado Técnico, 179)

HOLMES, J.G.; BAYLEY, H.S.; HORNEY, F.D. Digestion and absorption of dry and high-moisture maize diets in the small na large intestine of the pig. British Journal of Nutrition, v.30, n.3, p.401-410, 1973 .

HORWITZ, W. Official methods of analysis of Association of Official Analytical Chemists. 12.ed. Gaithersburg: AOAC, 1975. 1094p

JOBIM, C.C.; REIS, R.A.; RODRIGUES, L.R.A. et al. Presença de microrganismos na silagem de grãos úmidos de milho ensilados com diferentes proporções de sabugo. Pesquisa Agropecuária Brasileira, v.32, n.2, p.201-204, 1997.

JONGBLOED, A.W.; MROZ, Z.; VAN DER WEIJ- JONGBLOED, R. et al. The effects of microbial phytase, orgnic acids and their interaction in diets for growing pigs. Livestock Production Science, v.67, n.1-2, p.113-122, 2000.

LIMA, G.J.M.M.; SOUZA, O.W.; BELLAVER, C. et al. Determinação da composição química e do valor energético de silagem de milho para suínos. In: CONGRESSO NACIONAL DE MILHO E SORGO, 1998, Recife. Anais... Recife: Associação Brasileira de Milho e Sorgo, 1998. p.277. 
MATTERSON, L.D.; POTTER, L.M.; STUTZ, M.W. et al. The metabolizable energy of feed ingredients for chickens. Storrs: University of Connecticut, Agricultural Experiment Station, v.7, n.1, p.11-14, 1965. (Research Report).

MAZZUCO, H.; BERTOL, T.M. Mandioca e seus subprodutos na alimentação de aves e suínos. Concórdia: Embrapa Centro Nacional de Pesquisa de Suínos e Aves, 2000. 27p. (Circular Técnica, 25).

MOREIRA, I.; ROSTAGNO, H.S.; COELHO, D.T. et al. Determinação dos coeficientes de digestibilidade, valores energéticos e índices de controle de qualidade do milho e soja integral processados pelo calor. Revista da Sociedade Brasileira de Zootecnia, v.23, p.916-929, 1994.

PEKAS, J.C. Versatile swine laboratory apparatus for physiologic and metabolic studies. Journal of animal Science, v.27, n.5, p.1303-1309, 1968 .

PEREIRA, J.R.A.; ROSSI, J.R.P. Manual prático da avaliação nutricional dos alimentos. Piracicaba: Fundação de Estudos Agrários Luiz de Queiroz, 1995. 25p.

PHILLIP, L.E.; FELLNER, V. Effects of bacterial inoculation of high moisture ear corn on its aerobic stability, digestion and utilization for growth by beef steers. Journal of Animal Science, v.70, p.3178-3187, 1992.

POORE, J.R.; ECK, T.P.; SWINGLE, R.S. et al. Total starch and relative starch availability of grains. In: BIENAL CONFERENCE ON RUMEN FUNCTION, 20., 1989, Chicago. Proceedings... Chicago: [s.n], 1989. p.35.

RACKIS, J.J.; McGHEE, J.E.; LlENER, I.E. et al. Problems encountered in measuring trypsin inhibitor activity of soybean flour. Report of a collaborative analysis. Cereal Science Today, v.19, n.11, p.513-515, 1974.

ROONEY, L.W.; PFLUGFELDER, R.L. Factors affecting starch digestibility with special emphasis on sorghum and corn. Journal of Animal Science, v.63, p.1607-1623, 1986.

ROSTAGNO, H.S.; ALBINO, L.F.T.; DONZELE, J.L. et al. Tabelas brasileiras para aves e suínos: composição de alimentos e exigências nutricionais. Viçosa, MG: Editora UFV, 2000. 141p.

ROSTAGNO, H.S.; ALBINO, L.F.T.; DONZELE, J.L. et al. Tabelas brasileiras para aves e suínos; composição de alimentos e exigências nutricionais. 2.ed. Viçosa: UFV, Departamento de Zootecnia, 2005. 186p

UNIVERSIDADE FEDERAL DE VIÇOSA - UFV. Sistemas de Análises Estatísticas e Genéticas - SAEG. Versão 7.1. Viçosa, MG: Universidade Federal de Viçosa, 1997. 150p. (Manual do usuário).

SEAB/DERAL/CEPA/PR. [2005]. Acompanhamento da situação agropecuária no Paraná. Disponível em: <http://www.pr.gov.br/ seab/mandioca.pdf.> Acesso em: 13/12/2005.

SILVA, D.J.; QUEIROZ, J.S. Análise de alimentos: métodos químicos e biológicos. 2.ed. Viçosa, MG: Editora UFV, 2002. 235p.

SOARES, J.G.G. [2003]. Silagem de maniçoba: uma excepcional forragem. Disponível em: http://www.cpatsa.embrapa.br/artigos/ manicoba.html. Acesso em: 2/5/2003.

SOLOMON, T.E. Control of exocrine pancreatic secretion. In: JOHNSON, L.R. (Ed.). Physiology of the gastrointestinal tract. 3.ed. New York: Raven Press, 1994. p.1499-1529.

Van SOEST, P.J. Nutritional ecology of the ruminant. New York: Cornell University Press, 1994. 476p. 